\title{
Eco-Friendly Lead-Free Solder Paste Printing via Laser-Induced Forward Transfer for the Assembly of Ultra-Fine Pitch Electronic Components
}

\author{
Marina Makrygianni ${ }^{1}$, Filimon Zacharatos ${ }^{1} \mathbb{D}$, Kostas Andritsos $^{1} \mathbb{D}$, Ioannis Theodorakos ${ }^{1}$ (D), Dimitris Reppas ${ }^{2}$, \\ Nikolaos Oikonomidis ${ }^{2}$, Christos Spandonidis ${ }^{2}$ and Ioanna Zergioti ${ }^{1, *(D)}$ \\ 1 Physics Department, Zografou Campus, National Technical University of Athens, 15780 Athens, Greece; \\ marinam@mail.ntua.gr (M.M.); fzach@mail.ntua.gr (F.Z.); kandritsos@mail.ntua.gr (K.A.); \\ jtheod@mail.ntua.gr (I.T.) \\ 2 Prisma Electronics SA, 68132 Alexandroupolis, Greece; dimitris.reppas@prismael.com (D.R.); \\ n.oikonomidis@prismael.com (N.O.); c.spandonidis@prismael.com (C.S.) \\ * Correspondence: zergioti@central.ntua.gr
}

Citation: Makrygianni, M.; Zacharatos, F.; Andritsos, K.; Theodorakos, I.; Reppas, D.; Oikonomidis, N.; Spandonidis, C.; Zergioti, I. Eco-Friendly Lead-Free Solder Paste Printing via

Laser-Induced Forward Transfer for the Assembly of Ultra-Fine Pitch Electronic Components. Materials 2021, 14, 3353. https://doi.org/ $10.3390 /$ ma14123353

Academic Editor: Nikolaos A. Vainos

Received: 29 April 2021

Accepted: 11 June 2021

Published: 17 June 2021

Publisher's Note: MDPI stays neutral with regard to jurisdictional claims in published maps and institutional affiliations.

Copyright: (c) 2021 by the authors. Licensee MDPI, Basel, Switzerland. This article is an open access article distributed under the terms and conditions of the Creative Commons Attribution (CC BY) license (https:/ / creativecommons.org/licenses/by/ $4.0 /)$.

\begin{abstract}
Current challenges in printed circuit board (PCB) assembly require high-resolution deposition of ultra-fine pitch components ( $<0.3 \mathrm{~mm}$ and $<60 \mu \mathrm{m}$ respectively), high throughput and compatibility with flexible substrates, which are poorly met by the conventional deposition techniques (e.g., stencil printing). Laser-Induced Forward Transfer (LIFT) constitutes an excellent alternative for assembly of electronic components: it is fully compatible with lead-free soldering materials and offers high-resolution printing of solder paste bumps $(<60 \mu \mathrm{m})$ and throughput (up to 10,000 pads/s). In this work, the laser-process conditions which allow control over the transfer of solder paste bumps and arrays, with form factors in line with the features of fine pitch PCBs, are investigated. The study of solder paste as a function of donor/receiver gap confirmed that controllable printing of bumps containing many microparticles is feasible for a gap $<100 \mu \mathrm{m}$ from a donor layer thickness set at 100 and $150 \mu \mathrm{m}$. The transfer of solder bumps with resolution $<100 \mu \mathrm{m}$ and solder micropatterns on different substrates, including PCB and silver pads, have been achieved. Finally, the successful operation of a LED interconnected to a pin connector bonded to a laser-printed solder micro-pattern was demonstrated.
\end{abstract}

Keywords: Laser-Induced Forward Transfer; lead-free solder paste; PCB assembly; printed micropatterns

\section{Introduction}

The broad field of microelectronics has rapidly grown over recent decades, owing to novel materials and advanced fabrication technologies, which offer key-solutions to specific challenges. These technologies have also fostered the advancement of die-attach and chip-bonding techniques, which are essential for the packaging and assembly of microelectronic components. Conventional chip-bonding technologies spanning wire or thermosonic bonding and flip-chip bonding, have been improving in terms of throughput and reliability [1], but still cannot process flexible dies [2], nor accommodate the conformal attachment of dies on-chip with non-planar surface morphologies [3,4]. However, novel integration schemes and printable materials [5] have enabled innovative configurations, such as flexible and stretchable devices, aligned with environmental concerns for greener approaches [6]. These integration schemes, incorporating heterostructures and 3D architectures in many cases [7], have laid the foundations for a novel paradigm in interconnection technology: the digital and drop-on-demand fabrication techniques [8]. Demonstrations of the on-demand fabrication of interconnections have matched or even outperformed the conventional bonding technologies over the past 5 years. In particular, the inkjet printing of high-resolution bumps with $2.5 \Omega$ /bump resistance [9] and micro-dispensing with high 
precision and a vast range of deposited droplet volumes [10] have been demonstrated. Moreover, aerosol jet printing has delivered reliable $\mathrm{Au}$ and $\mathrm{Al}$ wire bonds [11], and more complex micro-dispensing schemes have been demonstrated for addressing hybrid bonding challenges [12]. Among these drop-on-demand digital technologies, laser direct printing has shown significant promise for breakthroughs in the high-resolution and digital deposition of materials interesting for die attachment and assembly applications: recently, laser direct printing of metal inks and pastes has shown outstanding potential for the fabrication of ultra-fine pitch [13,14], conformal [15] and even flexible interconnections [16]. The laser direct printing of highly viscous Ag nanopaste has been reported in [17] and [18] for the digital fabrication of 3D interconnects and side-wall contacts, respectively. Moreover, laser direct printing is fully compatible with lead-free and printable materials, enabling low temperature processing [19].

Within the family of laser direct printing technologies, laser printing relying on the laser-induced forward transfer (LIFT) technique stands out. LIFT has been progressing since its first demonstration in the early 1970s [20,21] and recently has been established as a direct printing method offering high-resolution and enabling direct deposition of features with minimized involvement of solvents and waste fluids (down to pL volumes). In particular, $20 \mu \mathrm{m}$ resolution at the liquid phase and around $3 \mu \mathrm{m}$ and $0.33 \mu \mathrm{m}$ at the solid phase using nanosecond (ns-LIFT) and femtosecond (fs-LIFT) pulsed lasers, have been demonstrated in [22] and [23] respectively. Over the years, it has been successfully employed as a digital and high-resolution tool for the fabrication of flexible circuits, organic devices and sensors [24]. Contrary to the conventional deposition processes, in which multiple, costly and time-consuming steps are involved, LIFT is a direct printing technique offering digital control over the size and the shape of the transferred voxel [25]. In this respect, LIFT is fully aligned with the trend for greener fabrication technologies, by being both a digital and an additive manufacturing process. The digital character enables significant cost saving without the need for masks and minimal non-recurring engineering times. The additive character fosters energy saving by minimizing the material waste. Moreover, LIFT is not limited by the viscosity of the material under transfer, as in the case of inkjet printing, since it is compatible with viscosities ranging from 1 up to more than $200,000 \mathrm{cP}[14,26]$. Therefore, it is compatible with both the environmentally friendly metal nanoparticles inks and the more viscous lead-free pastes. Combinational schemes of LIFT and laser micro-sintering in a single process chain have been previously introduced [27], resulting in metallic micropatterns for a large range of applications in flexible electronics including: the printing of flexible radio-frequency identification (RFID) antennas [28], the controllable and reproducible printing of microdots of silver (Ag) nanopaste (viscosity $>100,000 \mathrm{cP}$ ) on vertical sidewalls [29] for high performance electrical interconnections and recently the accomplishment of flexible interconnections [30]. Additionally, LIFT is capable of transferring pixels [31,32] and stacks of materials [33,34] in the solid phase [35], as well as intact dies or devices [36], and recently solder paste [37].

Here, we highlight the LIFT's potential for the digital and high-resolution (sub-100 $\mu \mathrm{m}$ ) printing of a type 5 , lead-free, solder paste by investigating the optimal process parameters on three different substrate cases, which represent most substrates involved in the dieattach processes: silicon $(\mathrm{Si})$, polymers and metallic PCB pads. Contrary to previous reports on the printing of solder paste bumps [14,37], in this work we demonstrate the actual bonding process by providing a proof of concept. In this respect, the methodology is structured to facilitate the solder paste bonding enabled by LIFT: (i) the donor's thickness is sufficiently high to ensure that the volume of the transferred solder paste is comparable to the volumes deposited by conventional processes. (ii) The selected receiver substrates are actual gold $(\mathrm{Au}) /$ nickel $(\mathrm{Ni}) /$ copper $(\mathrm{Cu})$ PCB pads, validating the compatibility with the PCB-assembly technology. (iii) We also demonstrate the versatility offered by LIFT, in terms of form factors, by printing micropatterns consisting of many solder paste bumps, to achieve controllable coverage of the effective area of the PCB pads. (iv) Using LIFT of Ag inks, a test platform comprising pads and electrodes was fabricated; solder paste 
micropatterns are deposited by LIFT on the designated pads, and then heated to achieve the bonding with the pin connectors which are in turn interconnected with a commercially available LED, whose operation is validated by applying the nominal voltage.

\section{Materials and Methods}

The configuration employed for these experiments consisted of two subsystems, the laser printing and the high-speed imaging system. The former comprised a ns diodepumped solid-state (DPSS) Nd:YAG laser (InnoLas Photonics GmbH, Krailling, Germany), operating at a wavelength of $532 \mathrm{~nm}$, providing $20 \mathrm{~W}$ maximum output power and up to $500 \mathrm{kHz}$ repetition rate, implementing the LIFT method (Figure 1) [38]. A repetition rate range of $10 \mathrm{kHz}$ was employed in this study and the corresponding pulse duration was $20 \mathrm{~ns}$, while the maximum output power used was $1.84 \mathrm{~W}$. In all experiments the laser spot size, which refers to the diameter of the spot size on the donor/carrier interface, was $100 \mu \mathrm{m}$. To print more complex patterns than single bumps, the laser beam was scanned with speeds up to $3 \mathrm{~m} / \mathrm{s}$ by using a galvanometric scanning system and an f-theta lens implementing a focal length of $170 \mathrm{~mm}$. The high-speed imaging system comprised a high-speed camera (Mini AX-100, Photron by Photron Europe Limited, Buckinghamshire, UK) coupled to the printing system, providing a maximum recording speed of 540,000 fps for this model. For these experiments, a recording speed of 122,400 fps (one frame every $8.17 \mu \mathrm{s})$ was found to be sufficient for the needs of the investigation on the jet formation and propagation. To illuminate the process, a commercially available light emitting diode (LED) was used, placed opposite to the high-speed camera and focused on the jet's formation plane, perpendicularly to the donor-receiver substrates. The camera was coupled with a $3 \times$ lens, operating as a magnification system. For the accurate calculation of the jet's velocity, a donor-receiver gap of more than $300 \mu \mathrm{m}$ was selected.

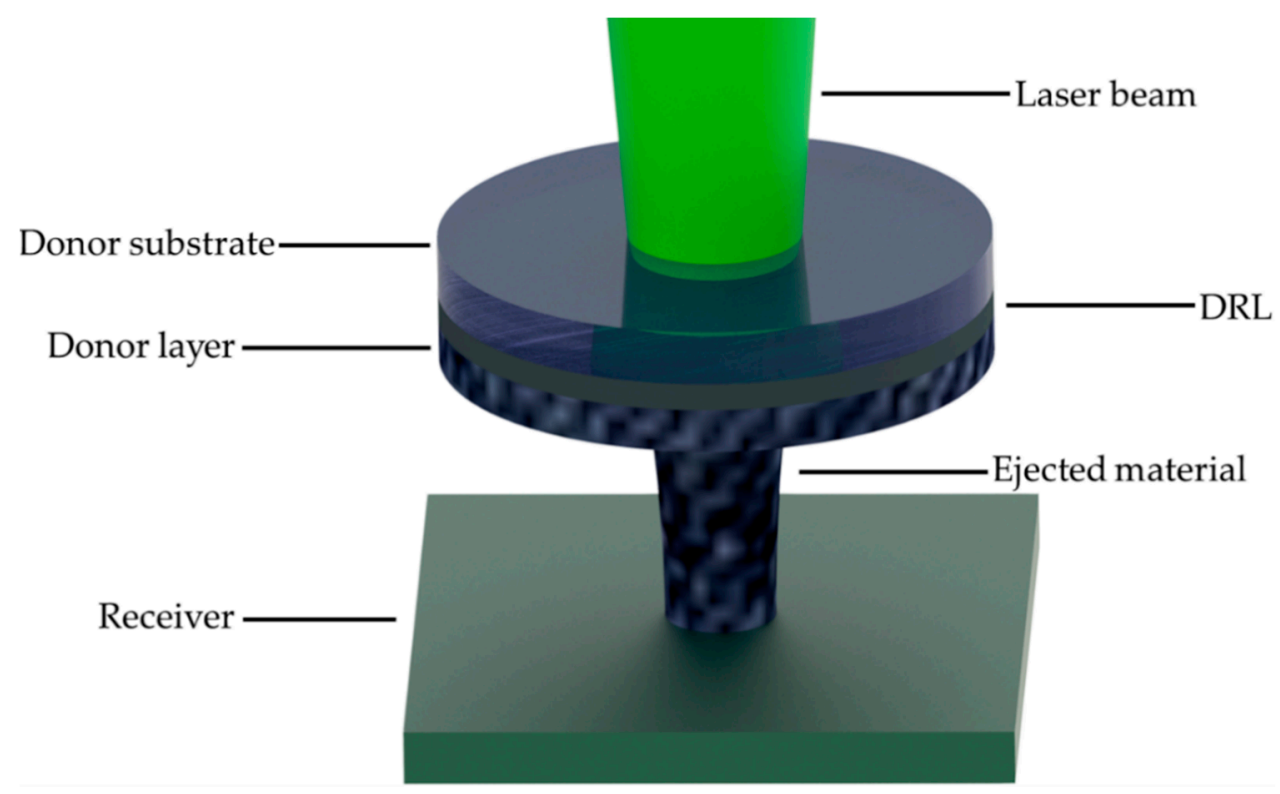

Figure 1. Schematic representation of the LIFT process of solder paste.

For the investigation of the ejection mechanism, a sacrificial layer was added to the donor material: a silver nanoparticle (Ag NP) ink layer was used as a dynamic release layer (DRL). Based on recently published findings [37], the use of DRL-assisted LIFT results in more reproducible, homogeneous and geometrically defined deposits, with respect to DRL-free LIFT when solder paste is involved. In particular, the main difference between DRL-free and DRL-assisted LIFT is the transfer mechanism of the solder paste. In the case of DRL-free LIFT, a voxel of solder paste separates from the donor and travels towards the receiver. Conversely, in the case of DRL-assisted LIFT and if the donor/receiver gap is 
in the order of $100 \mu \mathrm{m}$ or less, then a jet is formed which travels towards the receiver at a lower laser fluence ejection threshold, resulting in smoother depositions. Therefore, in this study, DRL-coated donors were employed. The DRL was prepared by spin coating a Ag nanoparticle ink (SunChemicals, $20 \mathrm{wt} . \%$ silver content) onto the donor substrate (quartz window, $50 \mathrm{~mm}$ dia $\times 3 \mathrm{~mm}$ thick purchased from UQG Optics) at $1000 \mathrm{rpm}$ for $30 \mathrm{~s}$. After the spin coating procedure, the Ag NP ink was dried at $75^{\circ} \mathrm{C}$ for $10 \mathrm{~min}$ and then sintered at $175^{\circ} \mathrm{C}$ for $10 \mathrm{~min}$, resulting in a thin (300 nm thick) Ag layer [6]. Silver was chosen as the DRL material for compatibility reasons, considering that the solder paste already contains a small percentage of silver. Finally, the solder paste donor layer was formed by coating thin films of the printable solder paste using an adjustable micrometer film applicator, whose blade height was set to four different levels: 15, 50, 100 and $150 \mu \mathrm{m}$. Profilometry was used to measure the surface roughness in the four different donors.

The average roughness $\left(R_{a}\right)$ was calculated using the following formula:

$$
R_{\mathrm{a}}=\frac{1}{L} \int_{0}^{L}|Z(x)| d x,
$$

where $Z(x)$ corresponds to the profile ordinates of the roughness profile and $L$ to the sampling length. $R_{a}$ was found to be $5.31 \mu \mathrm{m}, 5.24 \mu \mathrm{m}, 5.04 \mu \mathrm{m}$ and $3.77 \mu \mathrm{m}$, for donor thickness of $150 \mu \mathrm{m}, 100 \mu \mathrm{m}, 50 \mu \mathrm{m}$ and $15 \mu \mathrm{m}$, respectively. The quartz donor substrates used in this study feature very high transmission at $532 \mathrm{~nm}(>95 \%)$ and very low surface roughness $(<2 \mathrm{~nm})$.

For the receiver substrates, two different materials were chosen which are of interest for PCB packaging and assembly technology: semiconductors and polymers. For the printing investigation of discrete bumps, Dupont ${ }^{\circledR}$ Kapton ${ }^{\circledR}$ polyimide (PI) film (25 $\mu \mathrm{m}$ thickness) was chosen, due to its unique combination of mechanical and thermal properties and $\mathrm{Si}$ because of its establishment as a processing material in the manufacturing field. Furthermore, the metal pads $(\mathrm{Au} / \mathrm{Ni} / \mathrm{Cu}$ ) of a PCB were preferred as the receiver substrate for the printing of a solder paste design. According to the manufacturer (Eurocircuits), typical thicknesses of the metals comprising the PCB pads are within a range between 3 and $6 \mu \mathrm{m}$ for $\mathrm{Ni}, 0.05$ and $0.12 \mu \mathrm{m}$ for $\mathrm{Au}$.

Lead-free, no-clean solder paste, designed for use in Jet Printers, was purchased from Alpha Assembly Solutions. The aforementioned solder paste exhibits properties that are listed in Table 1. Briefly, solder paste consists of metallic microparticles suspended in a flux. Solder paste is categorized by type with regards to its solder particle size, and for example in type $5,80 \%$ of the particles are between 15 to $25 \mu \mathrm{m}$. In general, type 5 gives higher transfer efficiency than type 4 solder paste (particle size 20-38 $\mu \mathrm{m}$ ) and enables the enhanced printing for miniaturized components. All printed samples underwent a post-printing heating process, by oven-curing between $220^{\circ} \mathrm{C}$ for $15 \mathrm{~min}$ with a cooling time to room temperature of $30 \mathrm{~min}$, temperature indicated by the solder paste supplier.

Table 1. Solder paste properties.

\begin{tabular}{|c|c|c|c|c|c|}
\hline \multicolumn{2}{|c|}{ Solder Paste } & \multirow{2}{*}{$\begin{array}{l}\text { Type } \\
\text { Type } 5\end{array}$} & \multirow{2}{*}{$\begin{array}{l}\text { Particle Size } \\
\qquad 15-25 \mu \mathrm{m}\end{array}$} & \multirow{2}{*}{$\begin{array}{c}\text { Category } \\
\text { SAC305 } 96.5 \% \text { tin } \\
\text { 3\% silver } 0.5 \% \\
\text { copper }\end{array}$} & \multirow{2}{*}{$\begin{array}{c}\text { Flux } \\
\text { Zero halogen flux } \\
\text { formulation, } \\
\text { colorless flux } \\
\text { residue }\end{array}$} \\
\hline ALPHA JP-500 & $\begin{array}{l}\text { Lead-free, no-clean } \\
\text { solder paste for Jet } \\
\text { Printing }\end{array}$ & & & & \\
\hline
\end{tabular}

The Ag nanoparticle (NP) highly viscous ink employed for the laser printing and laser sintering of electrodes and pads, was procured from P.V. Nano Cell Ltd. (Migdal Ha'Emek, Israel) and consists of solid content, Sicrys ${ }^{\mathrm{TM}}$ nano silver particles, in the range $70-75 \mathrm{wt} . \%$. The realized test platform with this ink will be used for the proof of concept. 


\section{Results and Discussion}

The compatibility of LIFT with the selected solder paste material and their performance in key-challenges related to the PCB-assembly technology were investigated by conducting three different experimental studies: (i) the influence of the donor layer's thickness on the jet dynamics, (ii) the influence of the donor/receiver's gap on the printing quality and (iii) the contributions of the substrate. This section reports on the results derived from these three studies.

\subsection{Influence of Donor Thickness on Jet Dynamics}

An important parameter defining the laser printing quality is the donor thickness. To investigate the influence of the donor thickness on the jet propagation, frames extracted from the videos acquired with the high-speed camera setup at $122,400 \mathrm{fps}$ were processed. The donor-receiver gap was set at $500 \mu \mathrm{m}$ for the $15 \mu \mathrm{m}$ and $50 \mu \mathrm{m}$ thick donors, at $350 \mu \mathrm{m}$ for the $100 \mu \mathrm{m}$ thick donor and at $600 \mu \mathrm{m}$ for the $150 \mu \mathrm{m}$ thick donor, to extract a sufficient number of frames for the velocity calculation. Figure $2 \mathrm{a}$ shows a sequence of frames illustrating the solder paste's propagation for each donor case at their respective laser fluence transfer threshold. It is evident that the ejected solder paste breaks into smaller fragments until it reaches the receiver in the case of the thinner donors, while a more concrete bump propagates towards the receiver for the thickness of $100 \mu \mathrm{m}$. In the case of the $150 \mu \mathrm{m}$ donor, the donor-receiver gap is quite large $(600 \mu \mathrm{m})$ and as a result the ejected solder bump is multi-fragmented before reaching the receiver. In Figure $2 \mathrm{~b}$ the ejection velocities at laser fluences of 0.7 and $0.8 \mathrm{~J} / \mathrm{cm}^{2}, 1.0$ and $1.2 \mathrm{~J} / \mathrm{cm}^{2}, 1.4$ and $1.5 \mathrm{~J} / \mathrm{cm}^{2}$ and $1.7,2.0$ and $2.3 \mathrm{~J} / \mathrm{cm}^{2}$ are presented for the four different solder paste film thicknesses (15, $50,100,150 \mu \mathrm{m})$ on the donor. The term "ejection velocity" describes the average jet front velocity. More specifically, the velocity was calculated by a linear fit of the propagation length of the jet front before impact, as a function of the elapsed time for each successive frame extracted from the videos. As expected, the velocities increase as the laser fluence increases for each case. Furthermore, the increase in solder thickness on donor results in a shift of the threshold ejection fluence to higher fluences and towards lower average velocities of the travelling jet.

In general, excessive amount of solder paste on a PCB pad may cause solder bridging, whereas insufficient solder paste may lead to inadequate solder wetting between all components. In the case of stencil printing, a typical thickness of the applied solder is between 100 to $150 \mu \mathrm{m}$. Therefore, for consistency reasons, in this study we opted for the thickness of $100 \mu \mathrm{m}$ layer on the donor to be used in the investigation of the laser printing conditions for the individual printed bumps and a thickness of $150 \mu \mathrm{m}$ layer on the donor was used for printing solder paste micropatterns on PCB pads and Ag pads.

\subsection{Influence of the Donor-Receiver Gap}

In addition to the jet propagation study as a function of donor thickness, one other important parameter for successful printing is the understanding of the transfer mechanism of solder paste with respect to the donor/receiver gap. In this context, high-speed imaging experiments were carried out at different donor/silicon receiver gap distances. For these experiments two donor thicknesses were used, $100 \mu \mathrm{m}$ and $150 \mu \mathrm{m}$. Figure 3 shows still frame images illustrating solder paste transfer mechanism for each donor/receiver gap distance at their respective laser fluence transfer threshold $\left(1.4 \mathrm{~J} / \mathrm{cm}^{2}\right.$ and $1.7 \mathrm{~J} / \mathrm{cm}^{2}$ in the case of $100 \mu \mathrm{m}$ (Figure 3a) and $150 \mu \mathrm{m}$ (Figure 3b) thick solder paste donor, respectively). More specifically, in both cases a bridging is observed between the donor and the receiver substrate for donor/receiver gap up to $100 \mu \mathrm{m}$. In this bridging-based transfer, the formed solder paste jet continuously feeds the receiver for a period of more than $40 \mathrm{~ms}$ or until the donor is removed. The resulting printed bumps are of circular shape with a diameter between 50 to $60 \mu \mathrm{m}$ (as shown in Figure 3a,b bottom row). In contrast, in the case of donor/receiver gap $>100 \mu \mathrm{m}$ the solder paste transfer breaks into filaments/smaller 
fragments before reaching the receiver resulting in a multi-fragmented printed solder bump (as shown in Figure 3a,b bottom row).

(a)

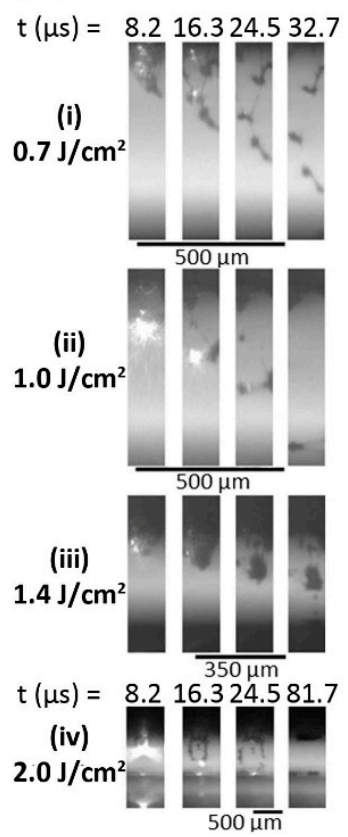

(b)

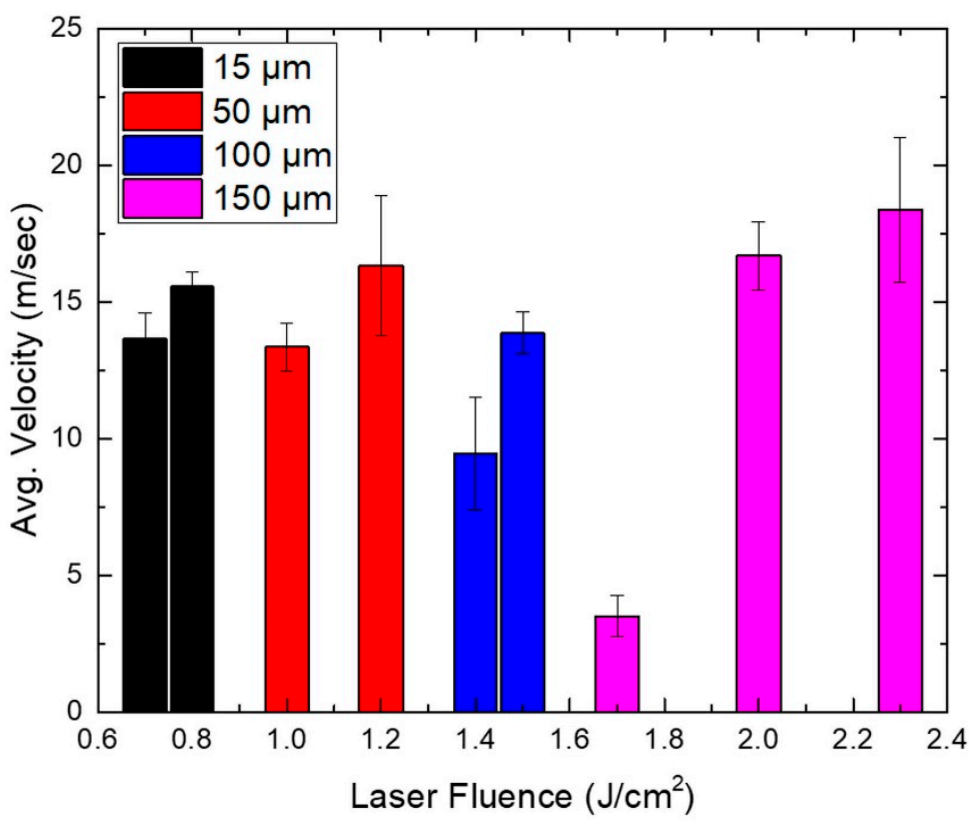

Figure 2. (a) Sequence of frames extracted from videos acquired at 122,400 fps for solder paste propagation from a donor layer thickness set by the film applicator at (i) $15 \mu \mathrm{m}$ and using laser fluence of $0.7 \mathrm{~J} / \mathrm{cm}^{2}$; (ii) $50 \mu \mathrm{m}$ and using laser fluence of $1.0 \mathrm{~J} / \mathrm{cm}^{2}$; (iii) $100 \mu \mathrm{m}$ and using laser fluence of $1.4 \mathrm{~J} / \mathrm{cm}^{2}$; (iv) $150 \mu \mathrm{m}$ and using laser fluence of $2.0 \mathrm{~J} / \mathrm{cm}^{2}$. The donor-receiver gap was set at (i,ii) $500 \mu \mathrm{m}$, at (iii) $350 \mu \mathrm{m}$ and at (iv) $600 \mu \mathrm{m}$. (b) Ejection velocities as a function of laser fluence for the four different solder paste donor thicknesses: $15 \mu \mathrm{m}$ (black), $50 \mu \mathrm{m}$ (red), $100 \mu \mathrm{m}$ (blue) and $150 \mu \mathrm{m}$ (magenta). The standard deviation resulting from a set of 10 repeats is also marked.

(a)
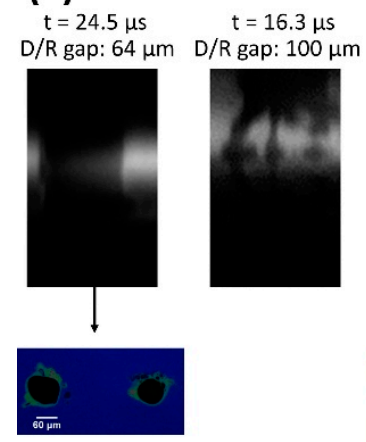

(b)

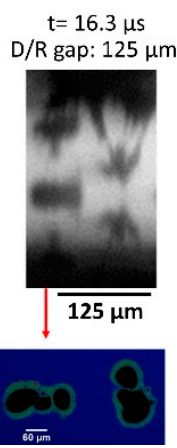

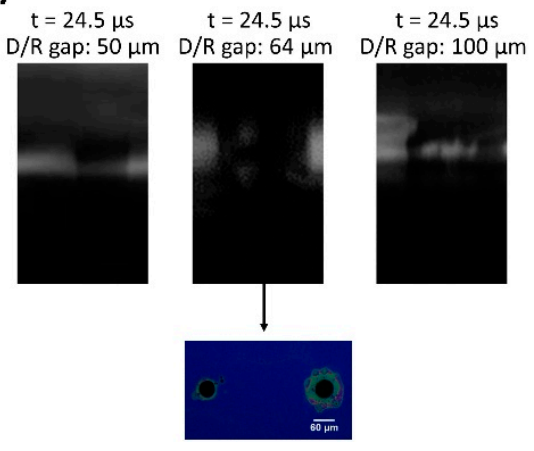

$\mathrm{t}=16.3 \mu \mathrm{s}$ D/R gap: $125 \mu \mathrm{m}$

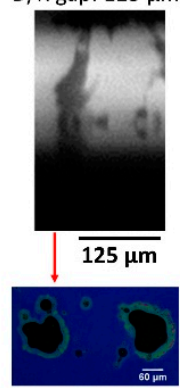

Figure 3. Still frame images extracted from videos acquired at 122,400 fps for a donor/receiver gap set at (a) $64 \mu \mathrm{m}, 100 \mu \mathrm{m}$ and $125 \mu \mathrm{m}$ (from left to right respectively) and from a donor layer thickness set by the film applicator at $100 \mu \mathrm{m}$ and using laser fluence of $1.4 \mathrm{~J} / \mathrm{cm}^{2}$; (b) $50 \mu \mathrm{m}, 64 \mu \mathrm{m}, 100 \mu \mathrm{m}$ and $125 \mu \mathrm{m}$ (from left to right respectively) and from a donor layer thickness set by the film applicator at $150 \mu \mathrm{m}$ and using laser fluence of $1.7 \mathrm{~J} / \mathrm{cm}^{2}$; Bottom row: Optical microscope images of laser-printed bumps on Si substrate at $1.4 \mathrm{~J} / \mathrm{cm}^{2}$ (a) and $1.7 \mathrm{~J} / \mathrm{cm}^{2}$ (b) for donor/receiver gap set at: $65 \mu \mathrm{m}$ and $125 \mu \mathrm{m}$.

It is concluded that the bridging effect that occurs for a donor-receiver gap $\leq 100 \mu \mathrm{m}$ is beneficial for the process due to the resulting more directional transfers, as opposed to larger gaps where the solder jet may oscillate or break during transfer. Consequently, in this work, the donor-receiver gap was fixed at $50 \mu \mathrm{m}$, for optimal printing result. 


\subsection{Printing on Si and Flexible Substrates}

The following results demonstrate the applicability of LIFT for the printing of bumps on widely used semiconductor and polymer substrates, in particular Si and Polyimide (as shown in Figure 4). At the optimized processing conditions (i.e., use of laser fluence just over transfer threshold, laser spot size $100 \mu \mathrm{m}$ ), a microarray of bumps was obtained on $\mathrm{Si}$ (Figure 4a) and polyimide (Figure $4 \mathrm{~b}$ ) substrate, for a laser fluence of $1.4 \mathrm{~J} / \mathrm{cm}^{2}$. It is observed that the flux residues cover the enclosed microparticles of the printed bumps shortly after printing, which are barely visible. The printed bumps on Si keep a round shape (Figure 4a), whereas the control over the printed bumps' shape on polyimide is proven more challenging with less uniform resulting shapes (Figure $4 \mathrm{~b}$ ). Polyimide has a very low surface energy in the order of $50 \mathrm{~mJ} / \mathrm{m}^{2}$ [39] and consequently, poor wetting behavior and adhesion is expected with respect to the higher surface energy Si substrate [40].
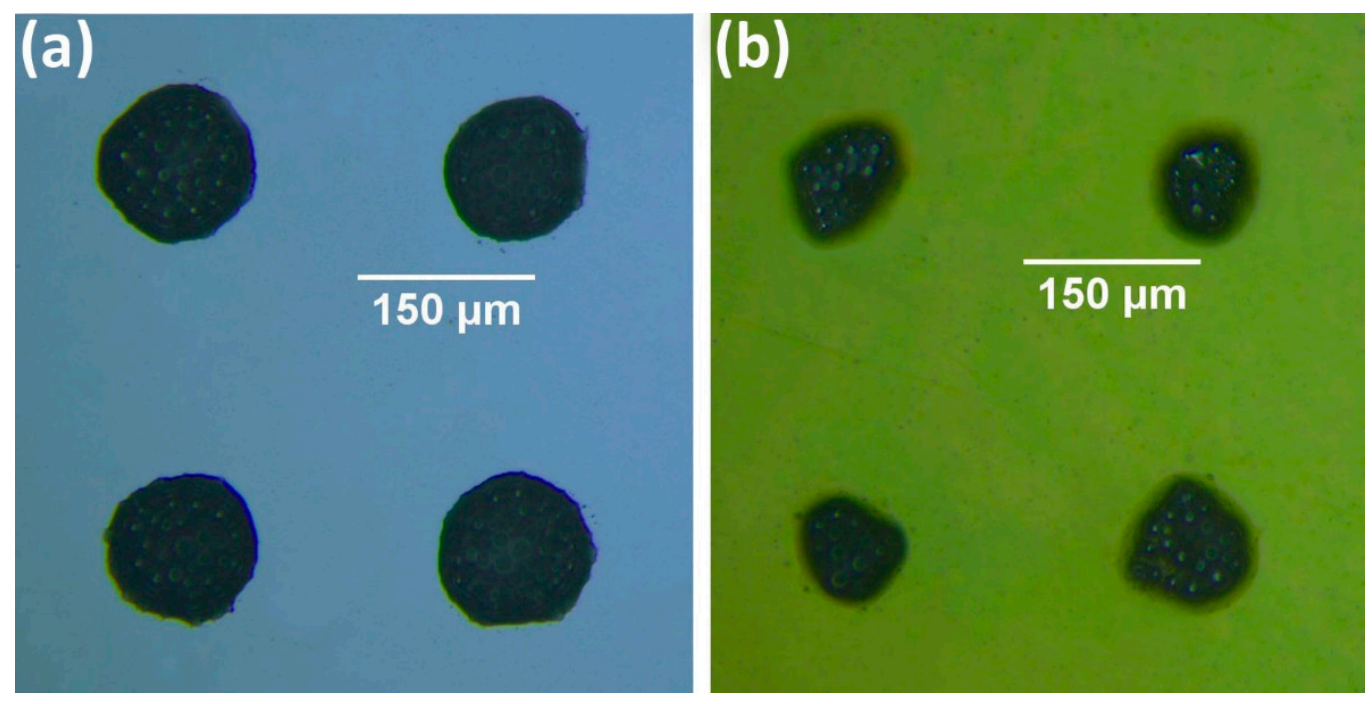

Figure 4. Optical microscope images of laser-printed bumps on (a) $\mathrm{Si}$, and (b) on polyimide. Laser fluence used for both cases is $1.4 \mathrm{~J} / \mathrm{cm}^{2}$. Before oven-curing, the flux covers the microparticles which are hardly visible. Donor-receiver gap was fixed at $50 \mu \mathrm{m}$ and donor layer thickness was set by the film applicator at $100 \mu \mathrm{m}$.

SEM characterization provided additional information about the microparticle morphology and form factors for both substrate cases, after oven-curing. In Figure 5, the bumps printed using the optimal laser fluence ranges for both $\mathrm{Si}$ and polyimide are presented. For increased fluence, the total volume of the bump and therefore the number of enclosed microparticles increases. The microparticle average diameter, is consistent in all cases, ranging from 12-22 $\mu \mathrm{m}$, in partial agreement with the solder paste's datasheet. In addition, the flux is almost completely removed owing to the heating occurring during the oven-curing procedure.

\subsection{Printing on PCB Pads}

Finally, the laser printing of solder bumps on a $\mathrm{Au} / \mathrm{Ni} / \mathrm{Cu}$ pad was investigated towards the direction of demonstrating that the reported process is fully compatible with the widely used pad materials in PCB technology. For the fabrication of patterns on the PCB pads, the donor-receiver gap was fixed at $50 \mu \mathrm{m}$ and the laser beam was scanned over the donor surface creating multiple jets, which form overlapping bumps (Figure 6a). First, a circular shape with length of $800 \mu \mathrm{m}$ and filled with five hatched lines was designed and fed to the scanning system software. The scanning speed was set at $1.5 \mathrm{~m} / \mathrm{s}$, yielding 16 laser pulses in the perimeter of the circle and 5 laser pulses in the central hatched line. The resulting printed pattern had a circular form of length similar to that of the circular design (Figure 6b) and an average height of $140 \mu \mathrm{m}$ (Figure 7a). Each bump was printed 
from a laser spot diameter of $100 \mu \mathrm{m}$, at a laser fluence of $2 \mathrm{~J} / \mathrm{cm}^{2}$ resulting in average bump diameter of $165 \mu \mathrm{m}$. Consequently, the circular solder pattern covers around $50 \%$ of the PCB pad.
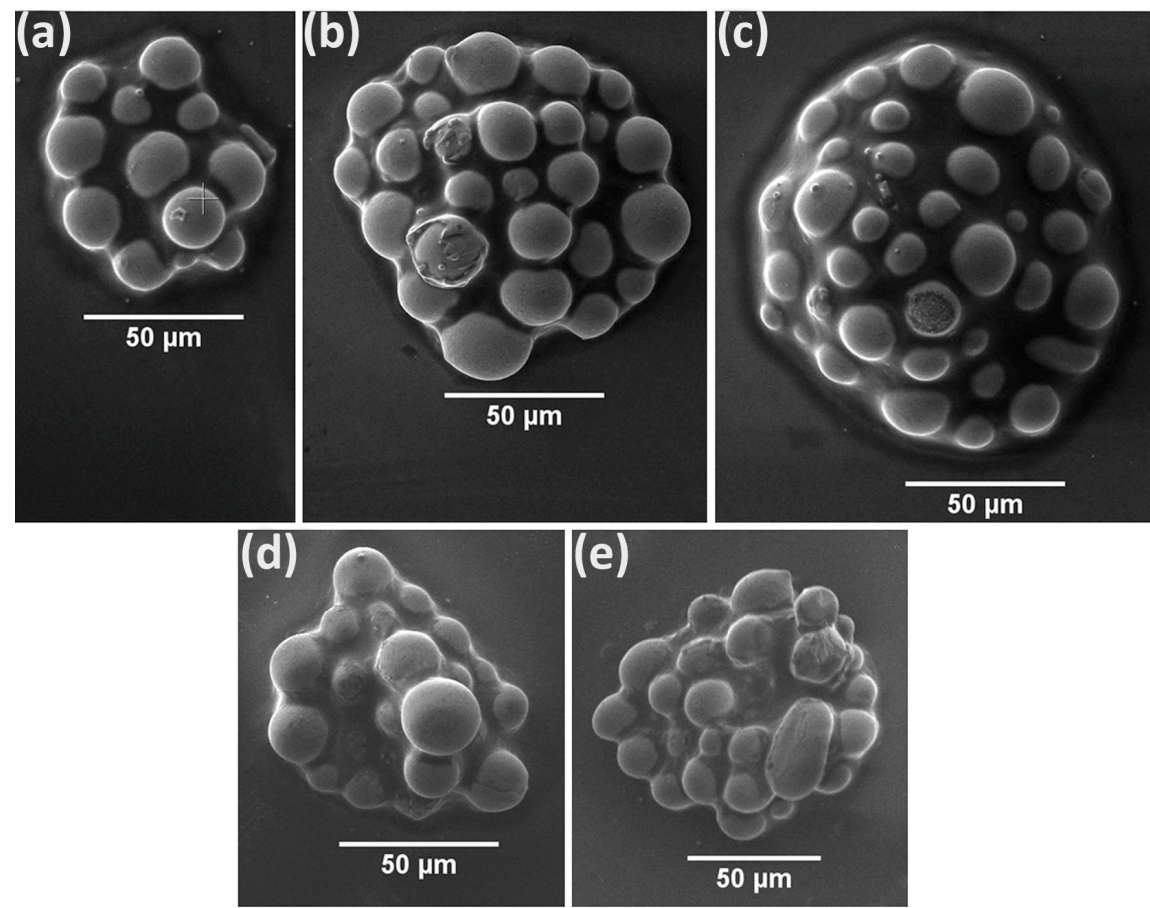

Figure 5. SEM characterization of laser-printed solder bumps post-oven-curing. (a-c) on Si, $1.3 \mathrm{~J} / \mathrm{cm}^{2}, 1.4 \mathrm{~J} / \mathrm{cm}^{2}, 1.6 \mathrm{~J} / \mathrm{cm}^{2}$, respectively. (d,e) on PI substrate, $1.3 \mathrm{~J} / \mathrm{cm}^{2}, 1.4 \mathrm{~J} / \mathrm{cm}^{2}$, respectively.

(a)

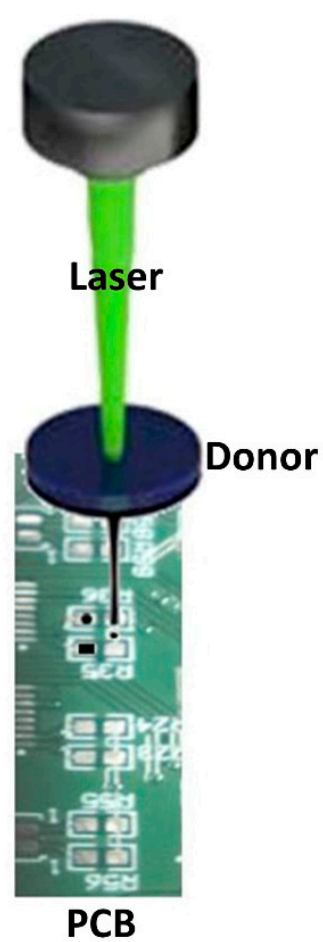

(b)

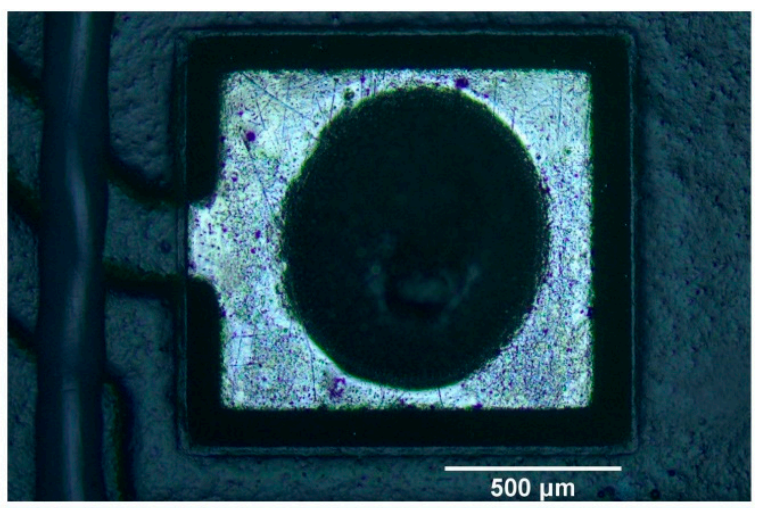

(c)

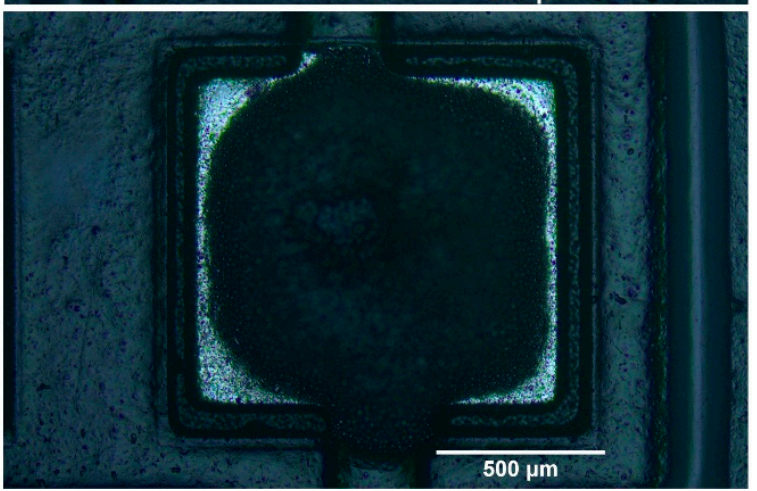

Figure 6. (a) Schematic of LIFT printing of solder paste on PCB pads, (b) resulting printed solder paste circular pattern at $2 \mathrm{~m} / \mathrm{s}$ (c) resulting printed solder square micro-pattern at $2 \mathrm{~m} / \mathrm{s}$. Donor-receiver gap was fixed at $50 \mu \mathrm{m}$ and donor layer thickness was set by the film applicator at $150 \mu \mathrm{m}$. 
(a)

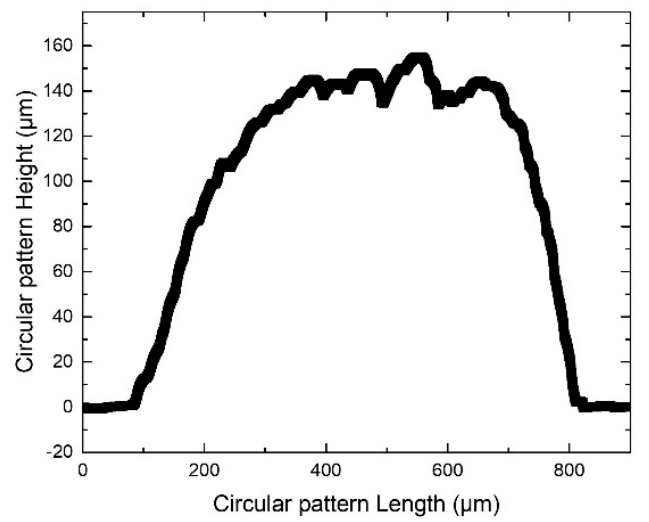

(b)

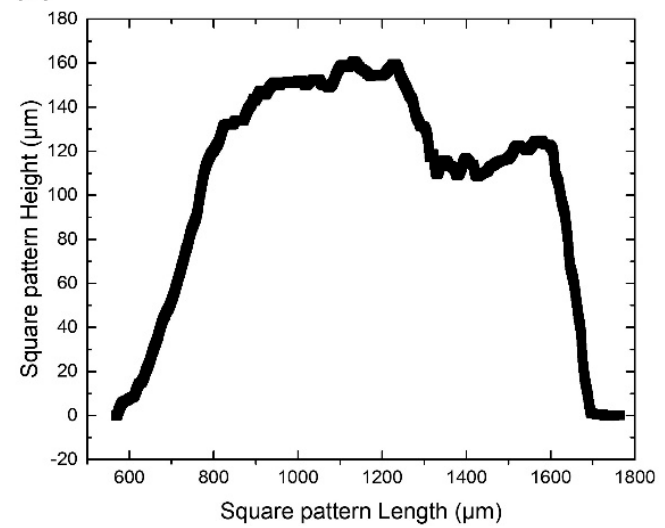

Figure 7. Profilometry measurement of (a) a circular printed pattern at $1.5 \mathrm{~m} / \mathrm{s}$, and (b) a square printed pattern at $1.5 \mathrm{~m} / \mathrm{s}$. Donor-receiver gap was fixed at $50 \mu \mathrm{m}$ and donor layer thickness was set by the film applicator at $150 \mu \mathrm{m}$.

Second, to maximize the coverage on the pad and the effective area available for bonding, a square pattern with length of $1100 \mu \mathrm{m}$ and filled with seven hatched lines was designed and fed to the scanning system, yielding a square solder micro-pattern as shown in Figure 6c. It must be noted that each bump has a diameter of $165 \mu \mathrm{m}$ and the digital control offered by LIFT ensures that the resulting covered printed area does not overflow the metallic pad's length of $1100 \mu \mathrm{m}$. The solder micro-pattern has an average thickness of $135 \mu \mathrm{m}$ and length around $1000 \mu \mathrm{m}$ (Figure $7 \mathrm{~b}$ ), offering around 90\% coverage, according to image analysis (area fraction) using ImageJ software.

From Figure $6 \mathrm{~b}, \mathrm{c}$ and Figure $7 \mathrm{~b}$, it can be observed that the profile of the upper part of the micropatterns collapses to a lower level of the order of 30-50 $\mu \mathrm{m}$. This can be attributed to the thixotropic nature of the solder paste material, where upon application of shear stress (caused by the laser pulse) [41] its viscosity decreases. Consequently, during impact of the solder bump on the receiver, the transferred microparticles may rearrange before the solder paste fully recovers its nominal viscosity value.

\subsection{Proof of Concept: Demonstration of LED Operation}

To demonstrate the bonding process enabled by LIFT, a commercially available LED was interconnected with pin connectors bonded to solder paste micropatterns which had been printed on silver pads. More specifically, the process for the realization of the test platform is described in the following steps. First, linear patterns and pads were laserprinted on a glass receiver substrate, as shown in Figure 8a. Prior to the LIFT experiment, the Ag NP ink was coated via an adjustable micrometer film applicator on a transparent carrier to form a $10 \mu \mathrm{m}$ thick donor substrate. Both the linear electrodes and the pads were fabricated using LIFT, by printing consecutive droplets with a scanning speed of $0.5 \mathrm{~m} / \mathrm{s}$ and a repetition rate of $10 \mathrm{kHz}$, at a donor/receiver gap distance of $50 \mu \mathrm{m}$. The process was duplicated in the case of the linear patterns to avoid any open circuits. Second, selective laser sintering was carried out by irradiating the printed linear patterns and pads with a scanning speed of $0.1 \mathrm{~m} / \mathrm{s}$ and a repetition rate of $60 \mathrm{kHz}$, which resulted in a $98 \%$ pulse to pulse overlap, while in the vertical to the printed linear patterns' direction, a $10 \mu \mathrm{m}$ distance between successive scanning passes was used, resulting in typical resistivities $<10 \times$ bulk Ag [27]. The outcome of this process is the evaporation of the ink's solvent and additives and the transformation of the printed nanoparticle pattern into a solid metal track, with significantly increased grain size. For the LIFT process, the laser fluence was set to $300 \mathrm{~mJ} / \mathrm{cm}^{2}$ and the spot size of the laser beam was $40 \mu \mathrm{m}$, and for the sintering process the laser fluence was set at $210 \mathrm{~mJ} / \mathrm{cm}^{2}$, and the spot size of the laser beam was $100 \mu \mathrm{m}$. The resulting Ag patterns are all conductive and their form factors were measured using profilometry: the pads have an average thickness of $1.6 \mu \mathrm{m}$ and length around $2000 \mu \mathrm{m}$ (as 
shown in inset of Figure 8a); the linear electrodes have an average thickness of $3 \mu \mathrm{m}$ and width around $190 \mu \mathrm{m}$ (as shown in inset of Figure 8b).

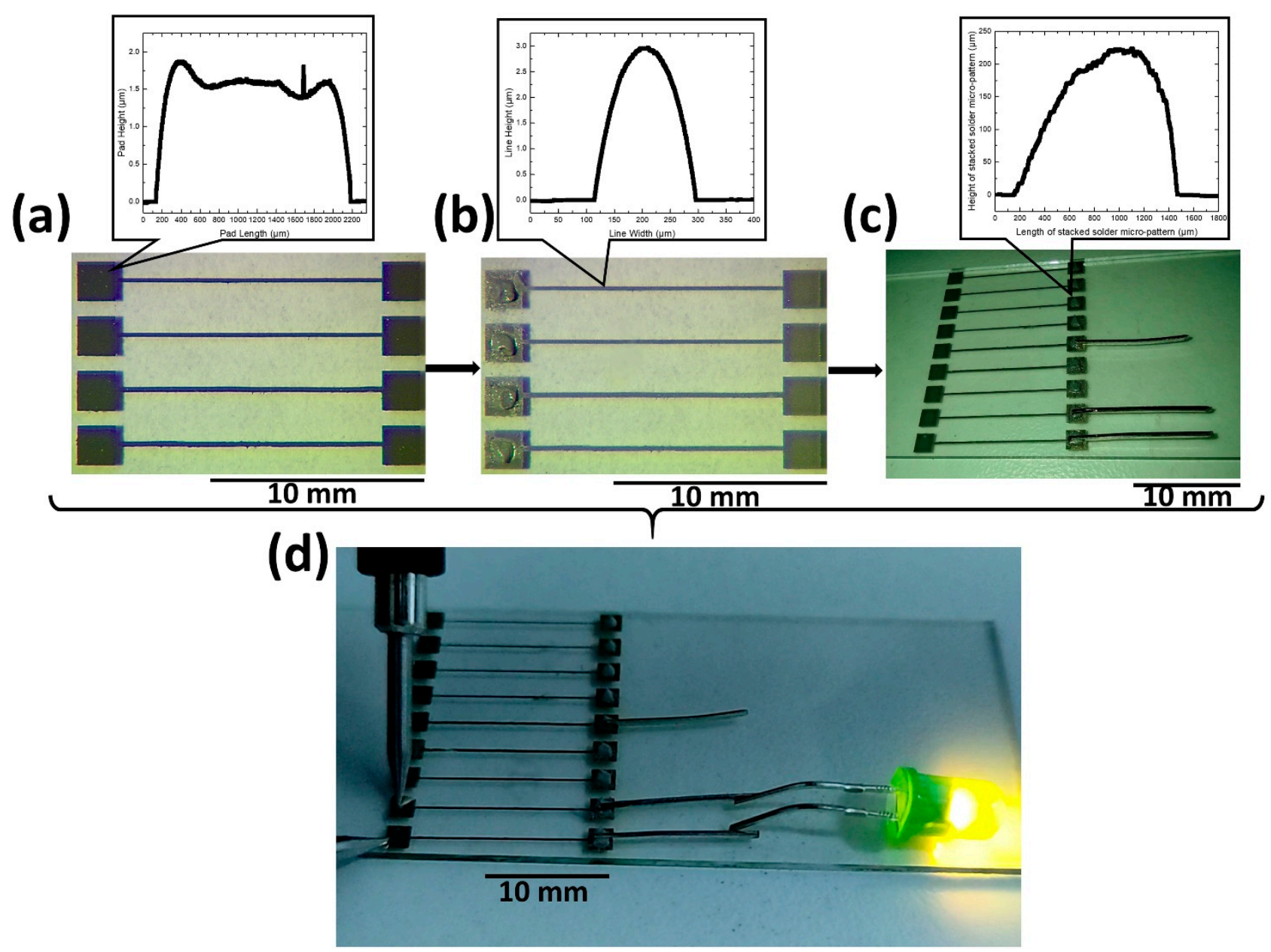

Figure 8. (a) Image of laser-printed and sintered linear patterns each connected to their respective pads; (b) Image of laserprinted solder paste stacked micropatterns on pads; (c) Image of the deposited pin connectors on the solder micropatterns prior to thermal treatment; Insets: Profilometry measurements of the LIFT printed and sintered pad (top left) and linear pattern (top middle) and of the LIFT printed solder paste micro-pattern (top right); (d) Operating a commercial LED by applying $3 \mathrm{~V}$ on LIFT printed and laser sintered silver pads.

Following the formation of electrodes, LIFT of solder paste square micropatterns was carried out on the electrode pads. For this, a square shape pattern with length of $1500 \mu \mathrm{m}$ and filled with 10 hatched lines was designed and fed to the scanning system software. The scanning speed was set at $1.5 \mathrm{~m} / \mathrm{s}$, the donor/ receiver gap was fixed at $50 \mu \mathrm{m}$, laser spot diameter at $100 \mu \mathrm{m}$, and laser fluence at $2 \mathrm{~J} / \mathrm{cm}^{2}$. The process was replicated to stack one more micro-pattern on top of the first. The resulting micro-pattern has an average thickness of $220 \mu \mathrm{m}$ and length around $1300 \mu \mathrm{m}$ (as shown in inset of Figure 8c).

Next, 3 pin connectors were embedded on the solder micropatterns prior to the thermal processing step described in Section 2 (Figure 8c). Successful bonding between the connectors and the solder micropatterns was observed after the oven-curing processing step. Finally, a LED was interconnected to the bonded pin connectors. To operate the LED, $3 \mathrm{~V}$ was applied on the silver pads via a Keithley 2400 current source. The successful operation of the LED was proven as shown in Figure 8d.

\section{Conclusions}

This work demonstrates that LIFT is compatible with lead-free solder paste and die attachment technology within a wide process window and for at least three different 
receiver materials: silicon, $\mathrm{PI}$ and $\mathrm{Au} / \mathrm{Ni} / \mathrm{Cu}$ metal. An investigation on the solder paste printing as a function of laser fluence confirmed that controllable printing of bumps containing many microparticles is feasible from a donor layer thickness set at $100 \mu \mathrm{m}$ on Si receiver substrate. Printing was also achieved for polyimide receiver substrate, despite its low surface energy value. For all cases, oven heating according to the solder paste specifications led to flux removal, exposing the metal microparticles. The laser printing process development was applied for the successful fabrication of millimeter sized solder paste patterns on top of PCB pads with sufficient surface coverage to ensure bonding. Finally, the successful operation of a LED was validated. The LED was interconnected to pin connectors bonded to laser-printed solder paste micropatterns on a test platform consisting of laser-printed and laser sintered Ag NP highly viscous ink.

Author Contributions: Conceptualization, M.M., F.Z., D.R., C.S., I.Z.; methodology, M.M., N.O., C.S., F.Z.; formal analysis, M.M., F.Z.; investigation, M.M., K.A., D.R., N.O., F.Z.; resources, N.O., C.S., I.Z.; writing—original draft preparation, M.M., F.Z.; visualization, K.A., I.T., M.M.; project administration, I.Z.; funding acquisition, I.Z. All authors have read and agreed to the published version of the manuscript.

Funding: This research has been co-financed by the European Union and Greek national funds through the Operational Program Competitiveness, Entrepreneurship and Innovation, under the call RESEARCH-CREATE-INNOVATE (project code: T1EDK-00814).

Institutional Review Board Statement: Not applicable.

Informed Consent Statement: Not applicable.

Acknowledgments: The authors would like to thank P.V. Nano Cell Ltd. (Migdal Ha'Emek, Israel) for providing the Ag nanoparticle highly viscous ink used for the realization of the test platform.

Conflicts of Interest: The authors declare no conflict of interest.

\section{References}

1. Zhong, Z.W.; Tee, T.Y.; Luan, J.E. Recent advances in wire bonding, flip chip and lead-free solder for advanced microelectronics packaging. Microelectron. Int. 2007, 24, 18-26. [CrossRef]

2. Looe, S.; Wang, S. Challenges \& solutions in the die attach process for micro thin die. In Proceedings of the 33rd IEEE/CPMT International Electronics Manufacturing Technology Conference (IEMT), Penang, Malaysia, 4-6 November 2008; pp. 1-5. [CrossRef]

3. Tsai, W.S.; Huang, C.Y.; Chung, C.K.; Yu, K.H.; Lin, C.F. Generational changes of flip chip interconnection technology. In Proceedings of the 12th International Microsystems, Packaging, Taipei, Taiwan, 25-27 October 2017; pp. 306-310, Assembly and Circuits Technology Conference (IMPACT). [CrossRef]

4. Delmdahl, R.; Pätzel, R.; Brune, J.; Müller, D. Superior microstructures for advanced package integration. Proceedings of SPIE 11268, Laser-Based Micro-and Nanoprocessing XIV, San Francisco, CA, USA, 2 March 2020; p. 1126813. [CrossRef]

5. Wood, E.P.; Nimmo, K.L. In search of new lead-free electronic solders. J. Electron. Mater. 1994, 23, 709-713. [CrossRef]

6. Pan, J.; Wang, J.; Shaddock, D.M. Lead-free Solder Joint Reliability-State of the Art and Perspectives. J. Microelectron. Electron. Packag. 2005, 2, 72-83. [CrossRef]

7. Bock, K.; Feil, M. Thin chips for flexible and 3D-integrated electronic systems. In Foldable Flex and Thinned Silicon Multichip Packaging Technology; Kluwer Academic Publishers: Boston, MA, USA, 2003; pp. 101-148.

8. Cruz, S.M.F.; Rocha, L.A.; Viana, J.C. Printing Technologies on Flexible Substrates for Printed Electronics. In Flexible Electronics; InTech: London, UK, 2018. [CrossRef]

9. Khorramdel, B.; Kraft, T.M.; Mäntysalo, M. Inkjet printed metallic micropillars for bare die flip-chip bonding. Flex. Print. Electron. 2017, 2, 045005. [CrossRef]

10. Lu, S.; Chen, X.; Zheng, H.; Zhao, Y.; Long, Y. Simulation and Experiment on Droplet Volume for the Needle-Type Piezoelectric Jetting Dispenser. Micromachines 2019, 10, 623. [CrossRef]

11. Stoukatch, S.; Laurent, P.; Dricot, S.; Axisa, F.; Seronveaux, L.; Vandormael, D.; Beeckman, E.; Heusdens, B.; Destiné, J. Evaluation of Aerosol Jet Printing (AJP) technology for electronic packaging and interconnect technique. In Proceedings of the 4th Electronic System-Integration Technology Conference, Amsterdam, The Netherlands, 17-20 September 2012; pp. 1-5. [CrossRef]

12. Palmer, J.A.; Summers, J.L.; Davis, D.W.; Gallegos, P.L.; Chavez, B.D.; Yang, P.; Medina, F.; Wicker, R.B. Realizing 3-D Interconnected Direct Write Electronics Within Smart Stereolithography Structures. In Proceedings of the ASME 2005 International Mechanical Engineering Congress and Exposition, Orlando, FL, USA, 5-11 November 2005; pp. 287-293. [CrossRef]

13. Shan, Y.; Zhang, X.; Chen, G.; Li, H. Laser direct printing of solder paste. AIP Adv. 2019, 9, 125306. [CrossRef] 
14. Mathews, S.A.; Charipar, N.A.; Auyeung, R.C.; Kim, H.; Piqué, A. Laser forward transfer of solder paste for microelectronics fabrication. In Proceedings of the Laser-Based Micro-Nanoprocessing IX, San Francisco, CA, USA, 7-12 February 2015; p. 93510Y. [CrossRef]

15. Pqué, A.; Kim, H.; Auyeung, R.C.Y.; Beniam, I.; Breckenfeld, E. Laser-induced forward transfer (LIFT) of congruent voxels. Appl. Surf. Sci. 2016, 374, 42-48. [CrossRef]

16. Pique, A.; Beniam, I.; Mathews, S.; Charipar, N. Laser Printed Interconnects for Flexible Electronics. APS 2016, 2016, A51. Available online: https:/ / ui.adsabs.harvard.edu/abs/2016APS..MARA51001P/abstract (accessed on 15 March 2021).

17. Wang, J.; Auyeung, R.C.Y.; Kim, H.; Charipar, N.A.; Piqué, A. Three-Dimensional Printing of Interconnects by Laser Direct-Write of Silver Nanopastes. Adv. Mater. 2010, 22, 4462-4466. [CrossRef] [PubMed]

18. Kim, H.; Duocastella, M.; Charipar, K.M.; Auyeung, R.C.Y.; Piqué, A. Laser printing of conformal and multi-level 3D interconnects. Appl. Phys. A 2013, 113, 5-8. [CrossRef]

19. Tan, H.W.; An, J.; Chua, C.K.; Tran, T. Metallic Nanoparticle Inks for 3D Printing of Electronics. Adv. Electron. Mater. 2019, 5, 1800831. [CrossRef]

20. Braudy, R.S. Laser Writing. Proc. IEEE 1969, 57, 1771-1772. [CrossRef]

21. Levene, M.L.; Scott, R.D.; Siryj, B.W. Material Transfer Recording. Appl. Opt. 1970, 9, 2260. [CrossRef]

22. Willis, D.A.; Grosu, V. Microdroplet deposition by laser-induced forward transfer. Appl. Phys. Lett. 2005, 86, 1-3. [CrossRef]

23. Banks, D.P.; Grivas, C.; Mills, J.D.; Eason, R.W.; Zergioti, I. Nanodroplets deposited in microarrays by femtosecond Ti:sapphire laser-induced forward transfer. Appl. Phys. Lett. 2006, 89, 193107. [CrossRef]

24. Logothetidis, S. Handbook of Flexible Organic Electronics: Materials, Manufacturing and Applications; Elsevier Inc.: Cambridge, UK, 2014. [CrossRef]

25. Munoz-Martin, D.; Brasz, C.F.; Chen, Y.; Morales, M.; Arnold, C.B.; Molpeceres, M. Laser-induced forward transfer of highviscosity silver pastes. Appl. Surf. Sci. 2016, 366, 389-396. [CrossRef]

26. Makrygianni, M.; Milionis, A.; Kryou, C.; Trantakis, I.; Poulikakos, D.; Zergioti, I. On-Demand Laser Printing of Picoliter-Sized, Highly Viscous, Adhesive Fluids: Beyond Inkjet Limitations. Adv. Mater. Interfaces 2018, 5, 1800440. [CrossRef]

27. Zacharatos, F.; Theodorakos, I.; Karvounis, P.; Tuohy, S.; Braz, N.; Melamed, S.; Kabla, A.; De la Vega, F.; Andritsos, K.; Hatziapostolou, A.; et al. Selective Laser Sintering of Laser Printed Ag Nanoparticle Micropatterns at High Repetition Rates. Materials 2018, 11, 2142. [CrossRef] [PubMed]

28. Koritsoglou, O.; Theodorakos, I.; Zacharatos, F.; Makrygianni, M.; Kariyapperuma, D.; Price, R.; Cobb, B.; Melamed, S.; Kabla, A.; de la Vega, F.; et al. Copper micro-electrode fabrication using laser printing and laser sintering processes for on-chip antennas on flexible integrated circuits. Opt. Mater. Express. 2019, 9, 3046. [CrossRef]

29. Papazoglou, S.; Makrygianni, M.; Zergioti, I.; Filippidou, M.; Chatzandroulis, S. All laser printed resistive chemical sensor: Fabrication and evaluation. In Proceedings of the 2016 IEEE SENSORS, Orlando, FL, USA, 30 October-3 November 2016. [CrossRef]

30. Andritsos, K.; Theodorakos, I.; Zacharatos, F.; Zergioti, I. The effect of electromigration on the lifetime and performance of flexible interconnections fabricated by laser printing and sintering. Appl. Surf. Sci. 2020, 506, 144968. [CrossRef]

31. Rapp, L.; Constantinescu, C.; Delaporte, P.; Alloncle, A.P. Laser-induced forward transfer of polythiophene-based derivatives for fully polymeric thin film transistors. Org. Electron. 2014, 15, 1868-1875. [CrossRef]

32. Makrygianni, M.; Ainsebaa, A.; Nagel, M.; Sanaur, S.; Raptis, Y.S.; Zergioti, I.; Tsamakis, D. Laser printed organic semiconductor PQT-12 for bottom-gate organic thin-film transistors: Fabrication and characterization. App. Surf. Sci. 2016, 390, 823-830. [CrossRef]

33. Shaw-Stewart, J.; Lippert, T.; Nagel, M.; Nüesch, F.; Wokaun, A. Red-green-blue polymer light-emitting diode pixels printed by optimized laser-induced forward transfer. Appl. Phys. Lett. 2012, 100, 203303. [CrossRef]

34. Heath, D.J.; Feinäugle, M.; Grant-Jacob, J.; Mills, B.; Eason, R.W. Dynamic spatial pulse shaping via a digital micromirror device for patterned laser-induced forward transfer of solid polymer films. Opt. Mater. Expr. 2015, 5, 1129-1136. [CrossRef]

35. Pohl, R.; Jansink, M.; Römer, G.R.B.E.; Huis in 't Veld, A.J. Solid-phase laser-induced forward transfer of variable shapes using a liquid-crystal spatial light modulator. Appl. Phys. 2015, 120, 427-434. [CrossRef]

36. Piqué, A.; Mathews, S.A.; Pratap, B.; Auyeung, R.C.Y.; Karns, B.J.; Lakeou, S. Embedding electronic circuits by laser direct-write. Microelectron. Eng. 2006, 83, 2527-2533. [CrossRef]

37. Makrygianni, M.; Margariti, E.; Andritsos, K.; Reppas, D.; Zacharatos, F.; Oikonomidis, N.; Spandonidis, C.; Zergioti, I. High Speed Soldering Using Laser Printing for the Assembly of Electronic Components. JLMN 2020, 15, 204-208. [CrossRef]

38. Theodorakos, I.; Kalaitzis, A.; Makrygianni, M.; Hatziapostolou, A.; Kabla, A.; Melamed, S.; de la Vega, F.; Zergioti, I. LaserInduced Forward Transfer of High Viscous, Non-Newtonian Silver Nanoparticle Inks: Jet Dynamics and Temporal Evolution of the Printed Droplet Study. Adv. Eng. Mater. 2019, 21, 1900605. [CrossRef]

39. Mittal, K.L. Adhesion Aspects of Thin Films; CRC Press: Boca Raton, FL, USA, 2005; Volume 2. [CrossRef]

40. Jothi Prakash, C.G.; Prasanth, R. Approaches to design a surface with tunable wettability: A review on surface properties. J. Mater. Sci. 2021, 56, 108-135. [CrossRef]

41. Kalaitzis, A.; Makrygianni, M.; Theodorakos, I.; Hatziapostolou, A.; Melamed, S.; Kabla, A.; de la Vega, F.; Zergioti, I. Jetting dynamics of Newtonian and non-Newtonian fluids via Laser-induced forward transfer: Experimental and simulation studies. Appl. Surf. Sci. 2019, 465, 136-142. [CrossRef] 